\title{
Solventless processing of conjugated polymers-A review
}

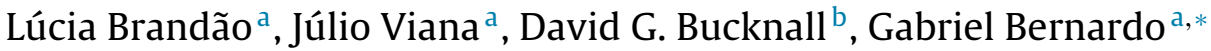 \\ a Institute for Polymers and Composites/I3N, University of Minho, 4800-058 Guimarães, Portugal \\ ${ }^{\mathrm{b}}$ Materials Science and Engineering, Georgia Institute of Technology, 801 Ferst Dr NW, Atlanta, GA 30332, USA
}

\section{A R T I C L E I N F O}

\section{Article history:}

Received 6 May 2014

Received in revised form 1 July 2014

Accepted 2 August 2014

\section{Keywords:}

Conjugated polymers

Solventless processing

Processing-structure-properties

relationships

\begin{abstract}
A B S T R A C T
The molecular mobility of polymers in their solid or molten states allows their processing without the need for toxic, "non-friendly" solvents. In this work, the main features of solvent-free processing methods applied to conjugated polymers are reviewed taking into consideration that these materials are largely used in a broad range of (opto-)electronic applications, including organic field-effect transistors, polymer light-emitting diodes and polymer photovoltaic devices. This review addresses the main advantages of processing such materials in their solid state offering an alternative fabrication scheme for several opto-electronic devices. Moreover, the properties of polymer-based opto-electronic devices are largely dependent on the conformations and orientations of polymer molecules in the corresponding polymer thin film layers; especially the ordering of conjugated polymer molecules in the active layer has been a topic of intense research in organic electronics. Therefore, this review also highlights the control of conjugated polymer molecule ordering when using solvent free processing techniques. Finally, conclusions and perspectives of solventless processed conjugated polymer molecules in organic electronics are addressed.
\end{abstract}

(c) 2014 Elsevier B.V. All rights reserved.

\section{Introduction}

After the discovery of intrinsically conducting polymers in the 1970s [1,2] which was later awarded the 2000 Nobel Prize in Chemistry, strong efforts have been performed on the development of this class of polymers as evidenced by the exponential increase in the number of papers published under this subject over the last decades [3]. Such interest stems from the remarkable set of properties that organic semiconductors possess including tunable semi-conductivity, tunable UV-Vis absorption properties, tunable photo- and electroluminescence, solar energy conversion capabilities (photovoltaic), energy storage and so on [4]. These properties have been widely exploited in a broad range of (opto) electronic applications, including polymer light-emitting diodes (PLEDs), organic photovoltaic cells (OPVs), organic thin-film transistors (OFETs) and lasers. So far, the most commercially used of these are PLEDs which can be used as backlight sources of liquid crystal displays or as flat-area light sources [5]. Also, solidstate lasing and super-luminescence have been observed in organic semiconductors through photo-pumping excitation [6]. Moreover,

\footnotetext{
* Corresponding author. Tel.: +00351 253510336.

E-mail address: gabriel.bernardo@dep.uminho.pt (G. Bernardo).
}

polymer solar-cells have shown an increased interest recently due to their strong potential for low-cost and ease of production, with efficiencies reaching $12 \%$ [7].

The strong research efforts on polymer semiconductors are related to the promise of their potential capability for producing low-cost, large-area, flexible electronic devices. New processes for large-size production are nowadays being actively developed targeting mainly organic photovoltaic applications [8]. In the research laboratory, semiconducting polymers are usually processed from solution by drop-casting, spin-coating or ink-jet printing. In the industrial setting, the techniques that are currently being focused on are ink-jet printing [9] and roll-to-roll processes [10] with specific efforts being made for production of long sheets with a real potential for short energy payback time [11]. In these processes, most of the organic semiconductors require dissolution in environmentally undesirable, toxic halogenated and aromatic solvents. Furthermore, the use of a solvent-based process to prepare polymer solar cells has been shown to be problematic owing to the very low solar cell efficiencies obtained (about 2\% when using organic solvents) when using a roll-to-roll process $[12,13]$. This efficiency declines even further when using nontoxic/nonpolluting solvents for the active layer deposition $(0.29 \%$ to $0.55 \%$ in the case of aqueous suspension inks $[14,15])$. Another setback, when using solvents to process conjugated polymers, is the frequent requirement to 


\begin{tabular}{|c|c|}
\hline \multicolumn{2}{|c|}{ Nomenclature } \\
\hline $6 \mathrm{~T}$ & oligothiophene $\alpha$-sexithiophene \\
\hline AFM & Atomic force microscopy \\
\hline \multicolumn{2}{|c|}{$\begin{array}{l}\text { BDMOPPV poly(2,5-bis(3,7-dimethyloctyloxy)-1,4- } \\
\text { phenylenevinylene) }\end{array}$} \\
\hline BDT & benzodithiophene \\
\hline BEHPPV & $\begin{array}{l}\text { poly(2,5-bis(2-ethylhexyloxy)-1,4- } \\
\text { phenylenevinylene) }\end{array}$ \\
\hline \multicolumn{2}{|c|}{$\begin{array}{l}\text { C12-pBTTT poly(2,5-bis(3-dodecyl-2-yl)-thieno[3,2- } \\
\text { b]thiophene) }\end{array}$} \\
\hline CDT-BT2 & $\begin{array}{l}\text { cyclopentadithiophene-benzothiadiazole } \\
\text { polymer }\end{array}$ \\
\hline \multicolumn{2}{|c|}{$\begin{array}{l}\text { diF-TESADT difluoro 5,11-bis(triethyl silylethynyl) anthra- } \\
\text { dithiophene }\end{array}$} \\
\hline DOPPV & poly(2,5-dioctyloxy-1,4-phenylenevinylene) \\
\hline & electroluminescence \\
\hline F8T2 & poly(9,9-dioctylfluorene-co-bithiophene) \\
\hline \multicolumn{2}{|c|}{$\begin{array}{l}\text { MDMOPPV poly(2-methoxy-5-(3,7-dimethyloctyloxy)-1,4- } \\
\text { phenylenevinylene) }\end{array}$} \\
\hline \multicolumn{2}{|c|}{$\begin{array}{l}\text { MEHPPV poly(2-methoxy-5-(2-ethylhexyloxy)-1,4- } \\
\text { phenylenevinylene) }\end{array}$} \\
\hline \multicolumn{2}{|c|}{$\begin{array}{l}\text { MOPPV poly(2-methoxy-5-octyloxy-1,4- } \\
\text { phenylenevinylene) }\end{array}$} \\
\hline$M_{w}$ & molecular weight \\
\hline OFET & organic field-effect transistor \\
\hline OPV & organic photovoltaics \\
\hline P3DDT & poly(3-dodecylthiophenes) \\
\hline P3HT & poly(3-hexyl-thiophene) \\
\hline \multicolumn{2}{|c|}{$\begin{array}{l}\text { PBTTT-C16 poly(2,5-bis(3-hexadecylthiophen-2- } \\
\text { yl)thieno[3,2-b]thiophene) }\end{array}$} \\
\hline PCL & $\operatorname{poly}(\varepsilon$-caprolactone $)$ \\
\hline PCBM & {$[6,6]-$ phenyl-C61- butyric acid methyl ester } \\
\hline PDMS & polydimethylsiloxane \\
\hline \multicolumn{2}{|c|}{$\begin{array}{l}\text { PEDOT:PSS poly(ethylenedioxythiophene): } \\
\text { poly(styrenesulfonate) }\end{array}$} \\
\hline PFO & poly(9,9-dioctylfluorene) \\
\hline PLEDs & polymer light-emitting diodes \\
\hline PPP & poly(p-phenylene) \\
\hline PPV & poly(1,4-phenylenevinylene) \\
\hline PT & polythiophene \\
\hline PTCDI & perylenetetracarboxylic diimide \\
\hline PTFE & poly(tetrafluoroethylene) \\
\hline PTTPs & [5,5']-bisphenyl-[2,2']-bithiophenes \\
\hline TFT & thin film transistor \\
\hline & melting temperature \\
\hline TIPS & 6,13-bis(triisopropylsilylethynyl)pentacene \\
\hline & gate voltage \\
\hline
\end{tabular}

derivatize the semiconducting species with solubilizing side chains. Not only does this compromise their electronic properties [16], it usually requires additional complex synthetic steps to derive the polymer precursors [17-19].

Conjugated polymers, like other polymers, can exhibit a large spectrum of different microstructures, ranging from completely amorphous to highly crystalline. Many electronic properties and processes are critically dependent on this molecular and supramolecular order that usually can be controlled during film formation processes $[20,21]$. For instance, it is generally accepted that there is no preferred orientation for the internal fields of the separated charges in polymer heterojunction solar cells [22] (i.e. electrons and holes created within the volume have no net resulting direction in which they should move) [23]. This is in correlation with the common solution processed active layers in organic photovoltaics; these films do not present any molecular alignment thus exhibiting largely isotropic properties [24]. However, thermal annealing post-treatment is usually required to increase the efficiency of the as-produced heterojunction solar cells by forming a more ordered morphology (increasing the crystallinity of the components) that creates better percolation pathways for charges to flow toward the corresponding electrodes [25-29]. In order to attain this, thermal annealing conditions need to be selected carefully because crystal overgrowth with an associated decrease of the device's efficiency may occur if too high annealing temperatures or too long annealing times are used [30,31]. In this respect, the ability to create a thin polymer donor-acceptor film on solid substrates with a reproducible, stable morphology and optimized physical properties is still a missing link in achieving ultimate performance potentials for conjugated conducting materials, especially for polymer solar cells.

In order to address these issues, molecular alignment is receiving significant attention in research on organic semiconductors [21,24,32]. Conjugated polymer molecules exhibit anisotropic properties due to their intrinsic characteristic of having electrons delocalized along the polymer backbone (main chain) leading to a $\pi$-stacking-induced molecular alignment. However, these desirable anisotropic properties are not observed in films prepared without use of techniques specifically chosen to induce polymer arrangement [33]. This molecular anisotropy and consequently anisotropic electron mobility can be used advantageously in circuit design, for example, to isolate neighboring components without requiring a large spatial separation or the patterning of the semiconductor layer [34]. In addition, in organic photovoltaic devices, where bias voltage is applied between top and bottom electrodes, it is expected that the increase in mobility due to crystal alignment in the direction perpendicular to the substrate will lead to improved power conversion efficiencies [35]. An example of this effect has been demonstrated in the use of a porous alumina template to prepare vertically aligned core-shell nanorods of P3HT and PCBM from the melt [22].

Besides the growing environmental concerns that created an urgent need to search for low-cost, environmentally friendly methods to process polymer semiconductors with "benign" solvents or alternative processes that do not require solvents at all, a lack of processes that can create a well-ordered, reproducible film morphology on solid substrates with a simple and straight forward methodology still exists. Processing of organic semiconductors in the solid state has been receiving attention lately due to their potential for a green methodology linked to a better control of film morphology. A vast majority of industrial thermoplastic polymer processing techniques are undertaken in the molten state, and there is potential to process semiconductor polymeric materials by exploiting this technology [36-40]. Additionally, processing such materials in their solid state, i.e. at temperatures below melting temperature, can also be an alternative straight-forward fabrication approach exploiting techniques such as calendaring, lamination and rolling that are also common methods employed in the polymer industries [41]. These methods therefore offer new opportunities for easy, scalable, simple methods to control polymer orientation and morphology, prerequisites for fabricating organic electronic devices with improved functionalities. Although some recent reviews have addressed closely related topics, namely the ordering of semi-conducting $\pi$-conjugated polymers [42-44] and its impact on the corresponding optoelectronic properties [45], this review is new in the sense that it summarizes different methods currently used to process conjugated polymers without the use of solvents as well as some of the techniques used to create wellordered morphologies using purely solid state processes. 


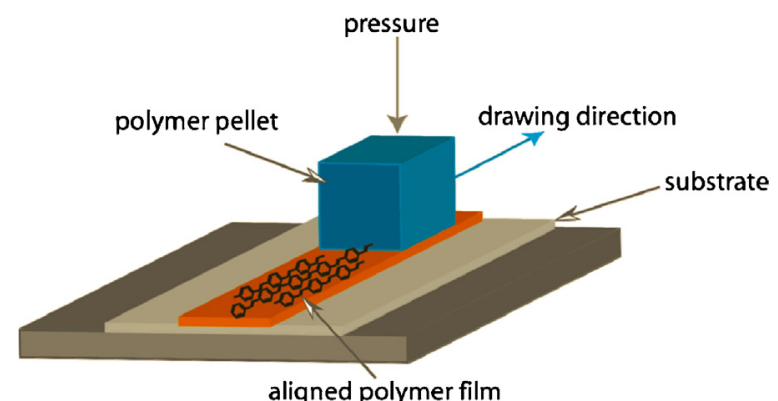

Fig. 1. Schematic representation of the friction transfer technique [24] (reprinted with permission).

\section{Friction transfer}

Friction transfer was first proposed by Makinson and Tabor [46] in the 1960s and demonstrated by Wittmann and Smith in 1991 [47] with the deposition of a thin film of poly(tetrafluoroethylene) (PTFE) on to a clean heated surface by squeezing and drawing a PTFE block. The resulting film contained highly oriented PTFE backbones along the drawing direction. Generally, in friction transfer, a pellet of the solid material to be deposited is drawn over a hot substrate under a critical compressive force required to deposit the aligned material (Fig. 1). Depending on the conditions used (temperature, pressure, sliding rate), it was shown that the thickness of the deposited film could be varied in the range from $2 \mathrm{~nm}$ to $100 \mathrm{~nm}$ [47-50]. Moreover, by the friction-transfer method, polymers can be aligned without using any secondary processing such as rubbing or thermal annealing.

The friction transfer technique was first applied to deposition of thin films of conjugated polymers in 1995 [51] with the aim of exploiting the intrinsic enhanced electron mobility properties that could be obtained from the electrons delocalized along aligned polymer backbones. Tanigaki's group successfully prepared friction transferred films from insoluble and soluble conjugated polymers, including polysilanes [52-54], poly( $p$-phenylene) (PPP) [51,53,54], poly( $p$-phenylenevinylene) and their derivatives. The resulting films exhibited high in-plane anisotropic properties as revealed by the highly-polarized photoluminescence in the plane parallel to the sliding direction [52,55,56]. Much more recently, Tanigaki et al. also reported the successful preparation of thin films of polyaniline (emeraldine base) [57] and of poly(3-butylthiophene) [58] by the friction transfer method. The same authors [59] have also reported the preparation of oriented thin films of the conjugated dye perylenetetracarboxylic diimide (PTCDI) vacuum deposited on the surface of oriented poly(tetrafluoroethylene) (PTFE) and poly ( $p$-phenylene) (PPP) substrates prepared by friction transfer at $300^{\circ} \mathrm{C}$ and $220^{\circ} \mathrm{C}$, respectively. They observed that the ability of oriented PPP to induce orientation of the PTCDI is better than that of oriented PTFE substrates, and they successfully fabricated polarization-sensitive photoelectric conversion devices by using the oriented PTCDI thin film on the PPP substrate.

Mizokuru et al. [35] reported the formation of oriented thin films of the oligothiophene $\alpha$-sexithiophene (6T) deposited on to in-plane-oriented polythiophene (PT) films formed by friction-transfer. Thin films of $6 \mathrm{~T}$ were evaporated onto an oriented $5 \mathrm{~nm}$ thick PT film, itself friction transferred at $250^{\circ} \mathrm{C}$, under vacuum. Tests indicated that the molecular axis of the $6 \mathrm{~T}$ molecules were aligned in the friction direction of the PT films, i.e. orientated parallel to the PT chain direction. In contrast, 6T molecules similarly deposited onto quartz and poly(ethylenedioxythiophene): poly(styrenesulfonate) (PEDOT:PSS)-coated silicon substrates aligned nearly perpendicular to the substrate. Heck et al. [60] studied the emission of

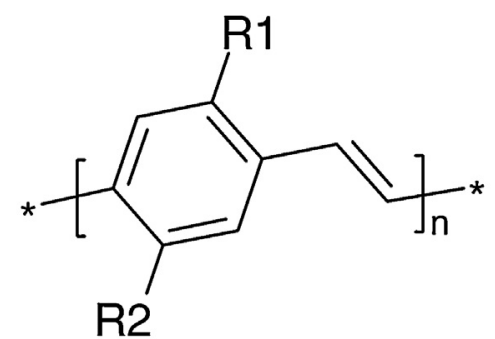

$\begin{array}{ll}\text { DOPPV } & : \mathrm{R}_{1}=\mathrm{R}_{2}=\text { octyloxy } \\ \text { BDMOPPV } & : \mathrm{R}_{1}=\mathrm{R}_{2}=3 \text {, -dimethyloctyloxy } \\ \text { BEHPPV } & : \mathrm{R}_{1}=\mathrm{R}_{2}=\text {-ethylhexyloxy } \\ \text { MOPPV } & : \mathrm{R}_{1}=\text { methoxy, } \mathrm{R}_{2}=\text { octyloxy } \\ \text { MDMOPPV } & : \mathrm{R}_{1}=\text { methoxy, } \mathrm{R}_{2}=3 \text {, } \text {-dimethyloctyloxy } \\ \text { MEHPPV } & : \mathrm{R}_{1}=\text { methoxy, } \mathrm{R}_{2}=\text {-ethylhexyloxy }\end{array}$

Fig. 2. Molecular structure of the PPV derivatives [61] (reprinted with permission).

electroluminescent (EL) devices of blue emitting oriented poly(9,9dioctylfluorene) (PFO) films prepared by friction transfer at $95^{\circ} \mathrm{C}$ with a thickness of $50 \mathrm{~nm}$, doped by orange emitting dye 6T. Very good polarization of the light emitted by these EL devices was observed due to orientation of PFO films. Very recently, the same authors also reported the production of the same oriented PFO films by friction transfer further doped with $6 \mathrm{~T}$ with an excellent control of the color of the emitted light by tuning the thickness of the $6 \mathrm{~T}$ film down to $4 \mathrm{~nm}$ [5].

Friction transfer was successfully used by Nagamatsu et al. to prepare highly ordered films of poly(3-hexylthiophenes) (P3HT) and poly(3-dodecylthiophenes) (P3DDT) with high inplane anisotropies [33]. P3HT and P3DDT films were friction transferred at $150^{\circ} \mathrm{C}$ and $100^{\circ} \mathrm{C}$, respectively, with film thicknesses lower than $100 \mathrm{~nm}$. These aligned films were observed to exhibit mobility increases of between 2 and 70 times those of conventional isotropic field-effect transistors devices prepared from non-aligned poly(3-alkylthiophene) films [32]. The same authors subsequently undertook a more comprehensive study in order to understand why some kinds of conjugated polymers did not form a uniform film by using friction-transfer. They studied the influence of substituting side-chains on 2,5alkoxy-substituted poly(1,4-phenylenevinylene) (PPV) in their capacity to form uniform films by friction transfer at temperatures from $80^{\circ} \mathrm{C}$ to $100^{\circ} \mathrm{C}$. Several substituted side-chain derivatives were studied: poly(2-methoxy-5-(2-ethylhexyloxy)1,4-phenylenevinylene) (MEHPPV), poly(2-methoxy-5-(3,7dimethyloctyloxy)-1,4-phenylenevinylene) (MDMOPPV), poly(2,5-dioctyloxy-1,4-phenylenevinylene) (DOPPV), poly(2,5bis(3,7-dimethyloctyloxy)-1,4-phenylenevinylene) (BDMOPPV), poly(2-methoxy-5-octyloxy-1,4-phenylenevinylene) (MOPPV) and poly(2,5-bis(2-ethylhexyloxy)-1,4-phenylenevinylene) (BEHPPV) (Fig. 2) [61]. It was observed that the friction-transferred film quality strongly depended on the side-chain structure, i.e. whether they are linear or branched, and the type of substitution, i.e. symmetric or unsymmetric. The structure of the side-chains was shown not to affect the friction transfer process only the polymer backbone alignment. The symmetric PPV derivatives (DOPPV, BDMOPPV and BEHPPV) were shown to form oriented and homogeneous films, with BEHPPV displaying the best quality film [61]. By contrast, none of the asymmetric PPV derivatives (MOPPV, BDMOPPV and MEHPPV) formed homogeneous films. Polymer crystallinity was also found to be an important factor for generating a homogeneous oriented film, with PPV crystallinity strongly depending on the kind of side-chain substitution. Symmetric PPV forming homogeneous oriented films were found to be highly crystalline, whilst asymmetric PPV that did not form homogeneous thin films are amorphous [61]. 


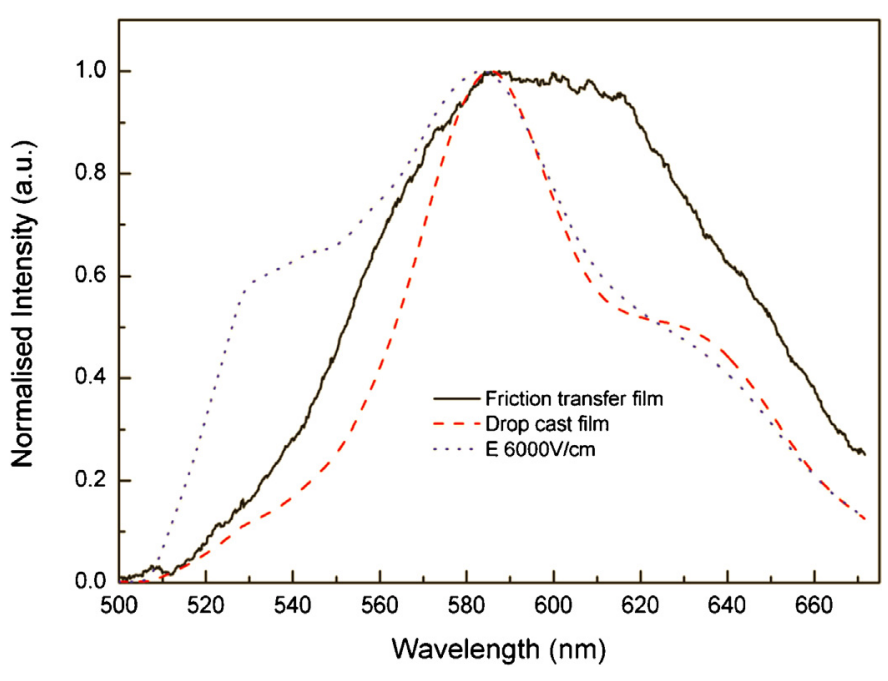

Fig. 3. Fluorescence emission spectra of a friction-transferred DPS-PPV film, a dropcast DPS-PPV film, and a high electric field $(6000 \mathrm{~V} / \mathrm{cm})$ induced DPS-PPV film [24] (reprinted with permission).

Hao et al. [24] reported thin film formation of a water-soluble poly(phenylenevinylene) (PPV) derivative with sulfonate containing side chains (DPS-PPV) on silica substrates by solvent-free friction transfer at $300^{\circ} \mathrm{C}$. Films were formed by "rods" of polymer aligned perpendicular to the drawing direction, contrasting with the behavior of comparable polymers, which tend to align along the drawing direction. In the friction-transferred polymer films short-lived fluorescent species are dominant, whereas long-lived emission species are favored in the drop-cast films. Consequently, friction transfer films exhibited a higher emission polarization ratio due to this alignment in comparison to a drop-cast DPS-PPV film and in comparison to a high electric field induced film (Fig. 3). In such friction transfer films a reduced emission quantum yield (as indicated by the shorter fluorescence decay behavior) was shown to result from the enhanced interchain interactions.

The formation of ordered poly(9,9-dioctylfluorene-cobithiophene) (F8T2) nanowires has also been reported by friction-transfer [62]. The F8T2 polymer, with a liquid-crystalline transition temperature at $217^{\circ} \mathrm{C}$, was cast into a block at $250^{\circ} \mathrm{C}$, this block was then friction transferred on to a glass substrate at $230^{\circ} \mathrm{C}$. The field-effect transistors fabricated with the F8T2 nanowire films, with a typical thickness of $400 \mathrm{~nm}$, exhibited a field-effect mobility along the wire direction 10 times higher than the mobility value obtained in transistors with the spin-coated polymer.

Very recently, Mizokuro et al. [63] performed a comparative study of the performance of OPV devices based on frictiontransferred P3DDT films and on similar spin-coated films and showed that devices based on friction-transferred films displayed higher OPV performances.

\section{Melt processing}

Melt processing is widely used in the polymer industry for being a solventless, environment-friendly and scalable process. However, the application of the method for semiconducting polymers is challenging because of their high melt temperatures [39] and relatively poor thermo-oxidation stability $[64,65]$. Some of the earlier reports on the melt processing of semiconducting polymers date back to the 1980's when Yoshino et al. prepared a flexible conductive polymer fiber by melt-spinning of poly(3-alkylthiophene)s [66], and others have shown that poly(3-alkylthiophene)s can be blended with common thermoplastic polymers and processed using conventional polymer melt processing techniques [67-69].
Much more recently, Muller et al. [37] synthesized diblock copolymers with poly(3-hexylthiophene)-polyethylene (P3HT-PE), with several different weight ratios of both blocks, where the P3HT block has higher melting and crystallization temperatures $\left(T_{m}=220^{\circ} \mathrm{C}, T_{c}=200^{\circ} \mathrm{C}\right)$ than the insulating $\mathrm{PE}$ moiety $\left(T_{m}=130^{\circ} \mathrm{C}, T_{c}=120^{\circ} \mathrm{C}\right)$. The antioxidant Irganox 1010 was added to all polymers in a weight percentage of $\sim 1 \%$. The authors studied the solid-state structure of the crystalline-crystalline diblock copolymers obtained after cooling from the melt, and showed that the structure consisted of (semi-) crystalline P3HT micellar-like entities dispersed in regions composed of amorphous and crystalline lamellar PE. The nature of the structures obtained was found to be dictated by the crystallization of the PE block, which solidified after P3HT as the system was cooled. These diblock copolymers formed classical spherulitic structures at low P3HT content. With P3HT contents exceeding 10-20 wt\% crystallization of PE is hindered by the P3HT blocks that arrange into columnar crystals. At still higher content, P3HT was found to be arranged into a lamellar micelle-type structure.

Qiu et al. [39] demonstrated that the active layer of organic transistors can be easily deposited from a semiconducting/insulating polymer blend using a melt process at $60^{\circ} \mathrm{C}$ integrating compounding with compression molding. Their "environment-friendly" solid-transfer method for fabricating organic thin-film transistors used a melt compressed polymer blend based on P3HT $\left(T_{m}=236^{\circ} \mathrm{C}\right)$ and $\operatorname{poly}(\varepsilon$-caprolactone $)(\mathrm{PCL})$ which is an insulating and biodegradable polymer with good low temperature meltprocessability $\left(T_{m}=56^{\circ} \mathrm{C}\right)$, as shown in Fig. 4. Qiu et al. showed that the P3HT content could be reduced to as low as $3 \mathrm{wt} \%$ without considerable degradation of the field-effect electronic properties imparted by the P3HT and yet maintaining excellent processability of the blends down to temperatures as low as $60^{\circ} \mathrm{C}$ due to the high PCL content. The resulting field-effect characteristics of the melt-compressed transistors were comparable to those of a solution processed device. The blend displayed outstanding mechanical properties with elongations at break exceeding 300\%, and has a potential use in biocompatible and biodegradable organic thin-film transistors, and could be compatible with a solid-state roll-to-roll process.

Muller et al. [70] addressed the charge carrier mobility of high pressure crystallized P3HT pellets. The P3HT pellets were solidified from the melt to room temperature under elevated pressure for two different P3HT molecular weights $\left(M_{w}=60\right.$ and $\left.344 \mathrm{~kg} \mathrm{~mol}^{-1}\right)$. For comparison, both polymers were also cast from solution. They observed an increased degree of crystallinity for the highpressure solidified specimen when compared with solution- and melt crystallized (at ambient pressure) samples. Moreover, they also concluded that pressure-induced solidification caused the formation of P3HT solids not only with a higher degree of bulk crystallinity but also with an increased crystal thickness. Significant enhancement in charge-carrier mobility in pressure solidified samples was also observed when compared to solution cast and molten samples (Fig. 5). However, the relatively high pressures (5000 bar) used in their work may prevent a useful practical application.

Processing of P3HT from the melt was also used to prepare semiconductor fibers that can be used for instance in "smart textiles". Fanous et al. have prepared P3HT microfibers by melt spinning with a significantly increased crystalline phase after drawing the fibers at $150^{\circ} \mathrm{C}$ (Fig. 6) [71].

\section{Processing of bulk solids (well below melting)}

Baklar et al. [41] have conducted a comprehensive study on the solid-state processing of several conjugated small molecular, oligomeric and polymeric compounds by compression molding 
(a)

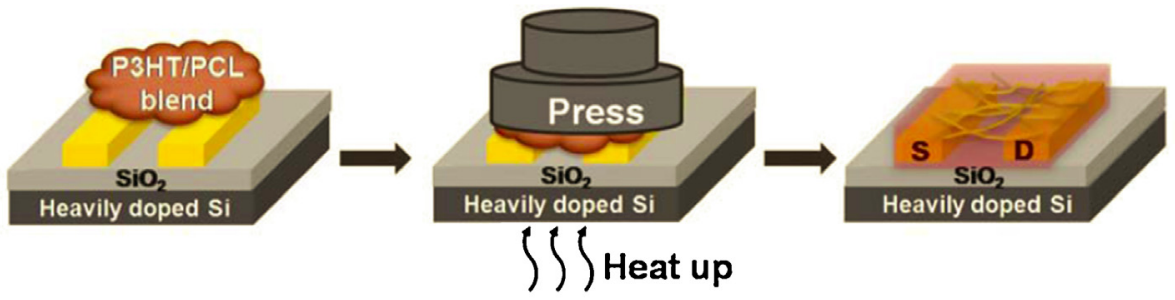

(b)

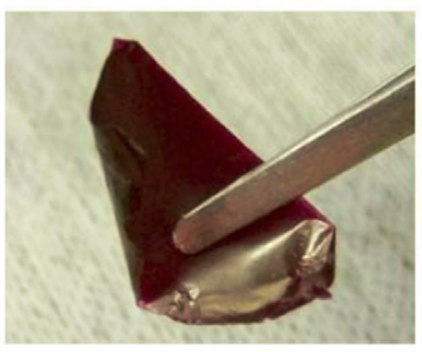

(c)

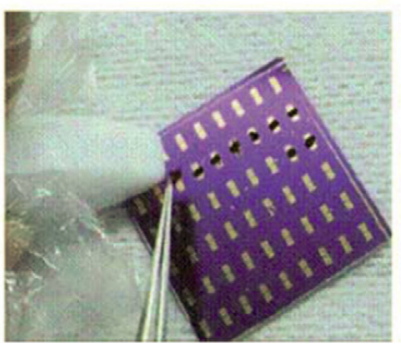

(d)

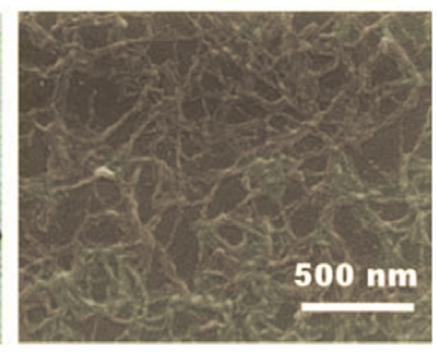

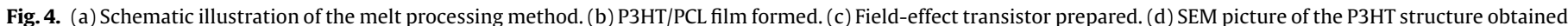
after PCL removal [39] (reprinted with permission).

at temperatures well below the melting point of the compounds (Fig. 7). They obtained highly ordered, robust films with thicknesses in the range of $1-200 \mu \mathrm{m}$ and observed high degrees of anisotropic order for both polymeric as well as small-molecular molecules [41]. Major radial molecular flow was shown to have occurred during the compression molding both for P3HT and
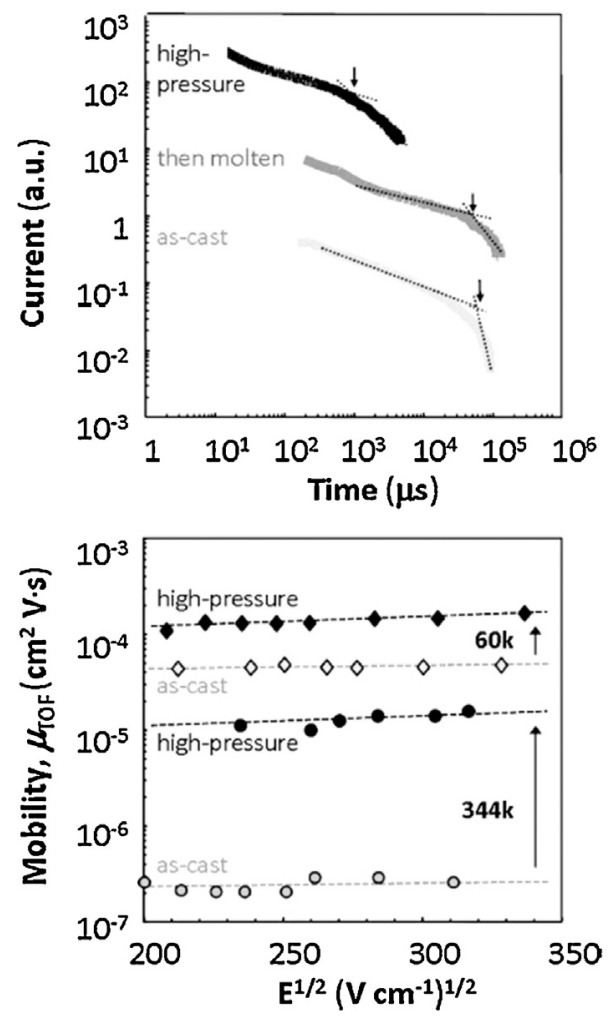

Fig. 5. (a) Time-of-flight (TOF) photoconductivity transients for P3HT of $M_{w}=344 \mathrm{~kg} \mathrm{~mol}^{-1}$, crystallized from solution (light gray) and the melt (dark gray: solidified at ambient pressure; black: solidified at $5 \mathrm{kbar}$ ). Transient arrival times $t t$ are indicated with arrows. (b) Field dependence of TOF charge-carrier mobility. A comparison between high-pressure-solidified (black symbols) P3HT and material crystallized from solution (light gray symbols) is shown [70] (reprinted with permission). the small-molecular 6T. This produced P3HT films composed of highly ordered, radially oriented macromolecules with the side chains perpendicular to the surface of the films. Moreover, no grain boundaries were observed in the fracture surfaces of P3HT and poly(2,5-bis(3-hexadecylthiophen-2-yl)thieno[3,2b]thiophene (PBTTT-C16) structures due to self-diffusion that "repaired" any energetically unfavorable boundaries. P3HT films also displayed remarkable mechanical robustness and toughness even when produced $200^{\circ} \mathrm{C}$ below their melting point [41].

Solid-state compressed polythiophene (PT) displayed a mirrorlike appearance with a reflectivity reaching $>35 \%$, comparable to that of silicon wafers, due to a higher density of the active moieties compared to the substituted polymer. The high reflectivity values of PT films exceed twice the reflectivity of compression molded P3HT, PCBM and $\mathrm{C}_{60}$ (around 17\%) [41]. Thus solid state processing offers a unique opportunity to fabricate functional thin solid films from compounds that are otherwise not capable of forming films (e.g., when processed from solution or the melt) [41].

The solid-state processed P3HT structures displayed three orders of magnitude enhancement in bulk charge transport properties compared to solution-cast films for high and low $M_{w}$ molecules (see Fig. 8). This is in agreement with the unidirectional

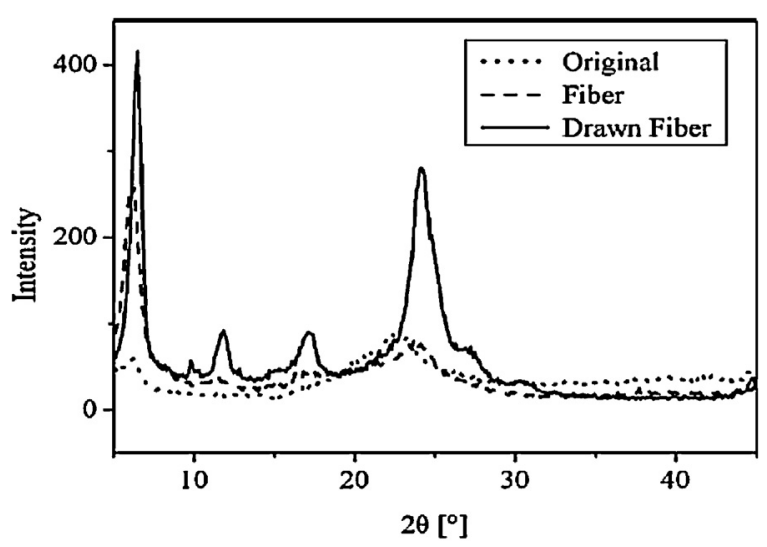

Fig. 6. XRD spectra of P3HT film, P3HT fiber and drawn P3HT fiber [71] (reprinted with permission). 
a
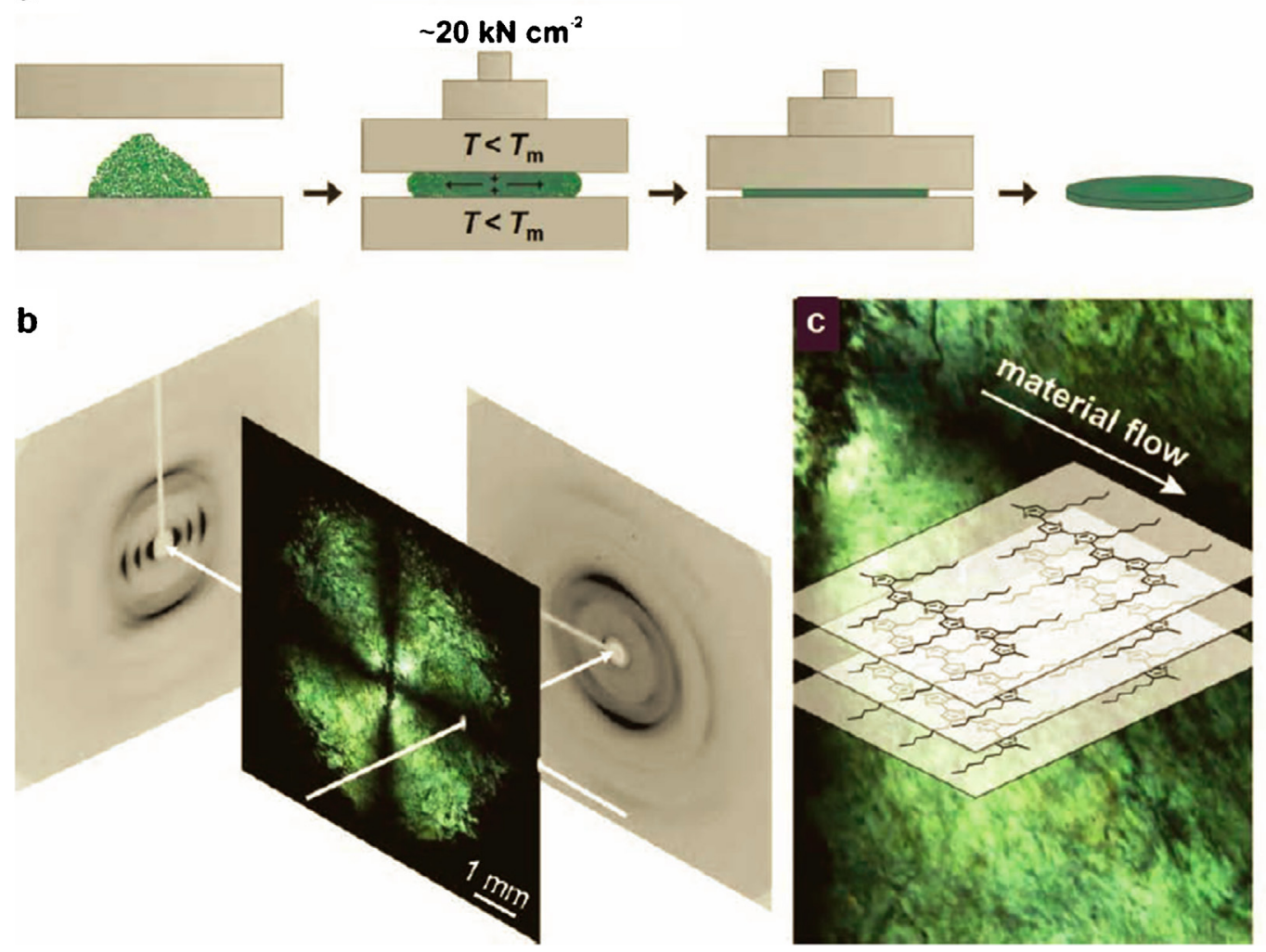

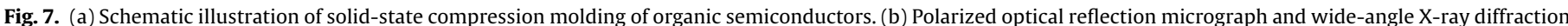

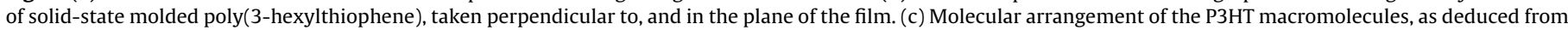
polarized optical microscopy and wide-angle X-ray diffraction [41] (reprinted with permission).

orientation of the macromolecular chains, despite the unfavorable arrangement of the insulating side chains being positioned along the transport direction [41]. It was also observed that the solidstate processed material when heated into the melt, displayed significantly lower charge transport, highlighting the fact that entirely different microstructures are produced with these two techniques (i.e., solid-state vs. melt processing). Similar observations were made for PBTTT-C16 for which bulk charge-carrier mobilities increased by about one order of magnitude with respect to solution-cast structures [41].

Field-effect transistors (FETs) assembled by directly molding of solid-state pressed films of P3HT, 6,13-bis(triisopropylsilyl ethynyl)pentacene (TIPS) and difluoro 5,11-bis(triethyl silylethynyl) anthradithiophene (diF-TESADT) on a bottomgate/bottom-electrode configuration demonstrated a strong field effect, i.e. current modulation by application of a gate voltage $\left(V_{\mathrm{G}}\right)$, while PCBM additionally exhibited ambipolar transport-i.e., transport of holes and electrons. The author stressed the ability to obtain field-effect charge-carrier mobilities with solid state processed films that are comparable to those recorded for solution-processed films based on the same FET geometry [41].

Treier et al. [72] prepared organic field-effect transistors produced by the annealing of powders of several organic semiconductors such as, cyclopentadithiophene-benzothiadiazole co-polymer (CDT-BTZ), benzodithiophene (BDT), poly(3hexylthiophene) (P3HT) and [5,5']-bisphenyl-[2,2']-bithiophenes (PTTPs) on gold SiOx surfaces without the use of any solvents. The simple thermal annealing of the sprinkled powders at $90^{\circ} \mathrm{C}$, i.e. below their melting temperatures, yielded functional transistors with some of the characteristics comparable to those of solutionprocessed devices. However, the annealing time was quite long (i.e., 20-70 h) and the homogeneity of the obtained films was poor.
More recently, Bernardo et al. reported, for the first time, the formation of P3HT fibers with diameters of 1 and $2 \mathrm{~mm}$ by solidstate extrusion processing at temperatures more than $100^{\circ} \mathrm{C}$ below the melting point of P3HT (see Fig. 9) [73]. The fibers produced by this method were continuous and mechanically robust with the macromolecular chains of P3HT preferentially oriented along the fiber axis. This approach allowed for processing of semiconductor polymers without the requirement of toxic, "non-friendly" solvents and at reduced processing temperatures where P3HT degradation rate is hindered [64]. The same group has also demonstrated the extension of the technique to produce extruded $\mathrm{P} 3 \mathrm{HT}$ ribbons with thicknesses of $\sim 0.15$ and $0.30 \mathrm{~mm}$ and width of $\sim 4 \mathrm{~mm}$ at temperatures below the polymer's melting temperature [74].

\section{Post processing of solution cast films}

Previous research has demonstrated that the molecular ordering and orientation of the conjugated polymers in the active layer significantly affects the corresponding device properties. However, the charge transport in conjugated polymer systems, exhibiting both amorphous and ordered phases with varying degrees of order, is complex due to the contribution of electronic processes at various length scales and a commonly accepted and widely applicable model still does not exist. In this respect, Noriega et al. [75] have recently proposed a unified model of how charge carriers travel in conjugated polymer films. According to these authors in high-molecular-weight semiconducting polymers, chain segments between aggregates (small domains with short-range ordering of a few molecular units) provide an efficient charge transport pathway between ordered regions and are not a rate-limiting step in the electrical transport process being the limiting charge transport step the trapping caused by lattice disorder in the aggregates. 

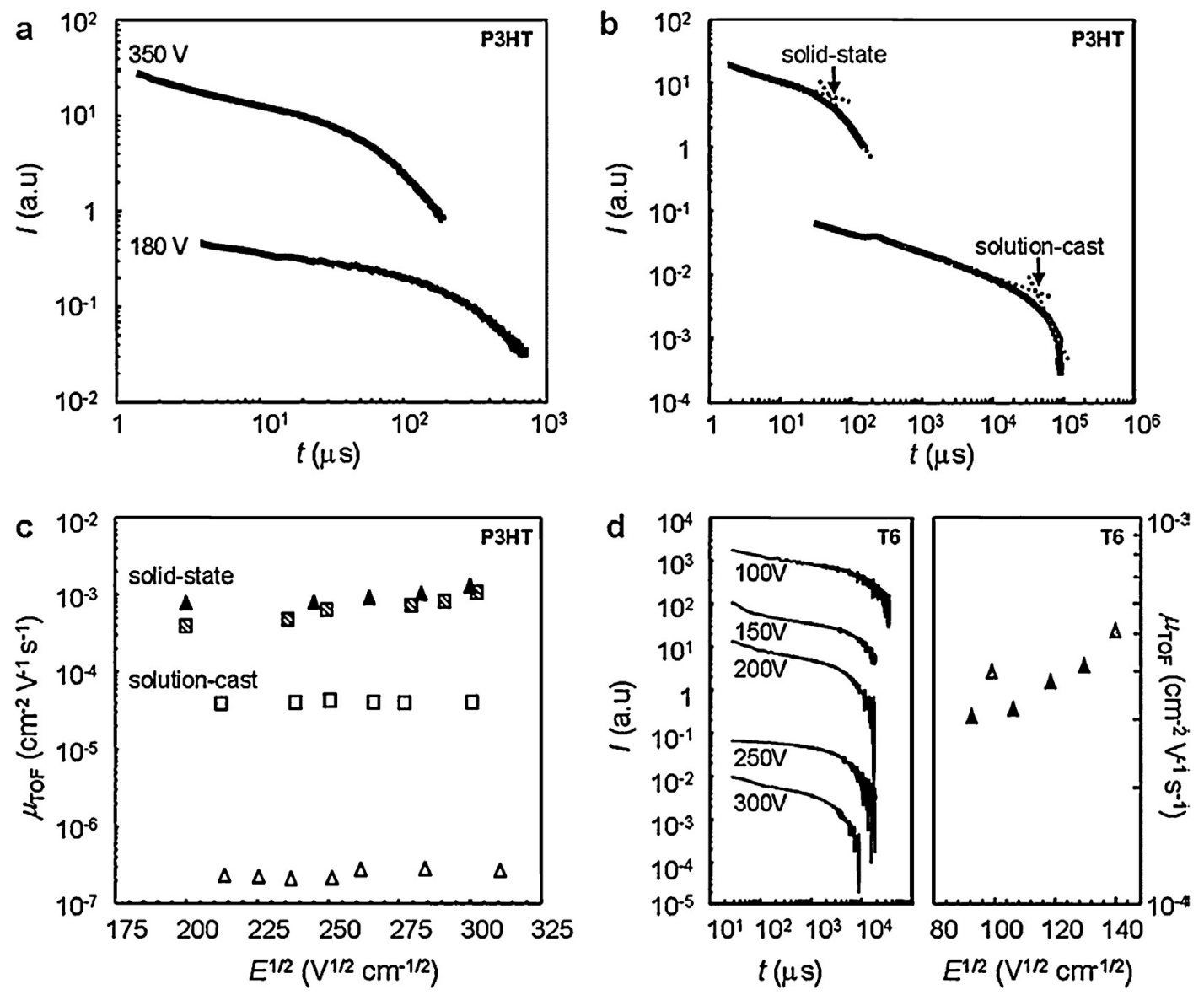

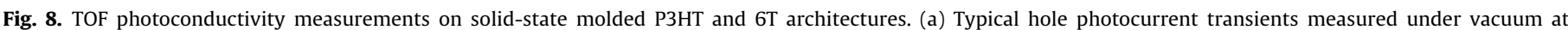

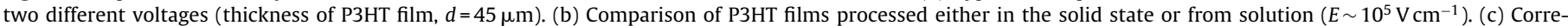

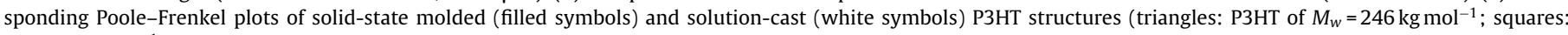

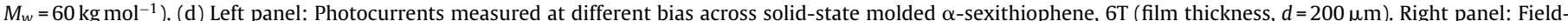

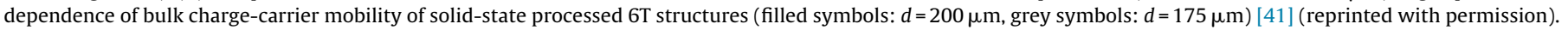

This section describes the solid state post processing of films that were initially cast from solution and then subjected to various post treatments to create alignment of the polymer molecules.

\subsection{Mechanical rubbing}

Derue et al. [76] successfully used rubbing and nanorubbing techniques for alignment of polymer chains in P3HT films. In the former technique, rubbing of a solution cast P3HT surface film with a velvet cloth at $190^{\circ} \mathrm{C}$ (Fig. 10) has resulted in crystalline aggregates on the surface which were perfectly aligned along the sliding direction. These were used as a template that induces chain orientation through the whole film thickness upon heating to the melting temperature. In the latter technique, nanorubbing was achieved using an Atomic Force Microscopy (AFM) stylus operating in contact mode, instead of the velvet cloth, to impart P3HT orientation with a nanometer resolution. This method was successfully used to unidirectionally nano-rub a $(10 \times 10) \mu \mathrm{m}^{2}$ area on a P3HT thin film surface.

Vohra et al. [77] assembled a graded bilayer solar cell based on poly(3-hexylthiophene) (P3HT)-[6,6]-phenyl- $\mathrm{C}_{61}$-butyric acid methyl ester (PCBM) donor-acceptor system by rubbing the P3HT layer prior to PCBM deposition. It was shown that rubbing P3HT induces the formation of a donor-acceptor concentration gradient in the vertical direction with the P3HT crystallites undergoing a molecular reorientation from edge-on to face-on configuration with an overall improvement of the charge transport in the vertical direction (Fig. 11).

Brinkmann's group studied the mechanism of orientation of P3HT polymer chains by rubbing, with particular emphasis on the effect of molecular weight $\left(M_{w}\right)$ on the in-plane orientation of the rubbed films [78]. They found that rubbing of the films causes orientation of the chains parallel to the rubbing direction and the in-plane orientation achieved in the films increases when the $M_{w}$ of P3HT decreases. Later the same authors studied the orientation effects in polymer composite films, of P3HT with CdSe nanorods, prepared by mechanical rubbing [79]. They observed that, similarly to the P3HT chains, the CdSe nanorods also align parallel to the rubbing direction. However, and more interestingly, they also found that the level of in-plane orientation of both the nanorods and the polymer chains decreases when the concentration of CdSe nanorods in the polymer matrix increases. Rubbing was also used by the same group to orient the conjugated polymer poly(2,5-bis(3dodecyl-2-yl)-thieno[3,2-b]thiophene) (C12-pBTTT), on top of an heated sample holder, exploiting the increased plasticity of the conjugated polymer films in the temperature range between 50 and $125^{\circ} \mathrm{C}[80]$. The in-plane alignment of the C12-pBTTT chains and the size of the oriented domains was found to increase with the temperature of the film during rubbing, resulting in high hole mobility anisotropies as measured in bottom gate, bottom contact OFET devices. 
(a)
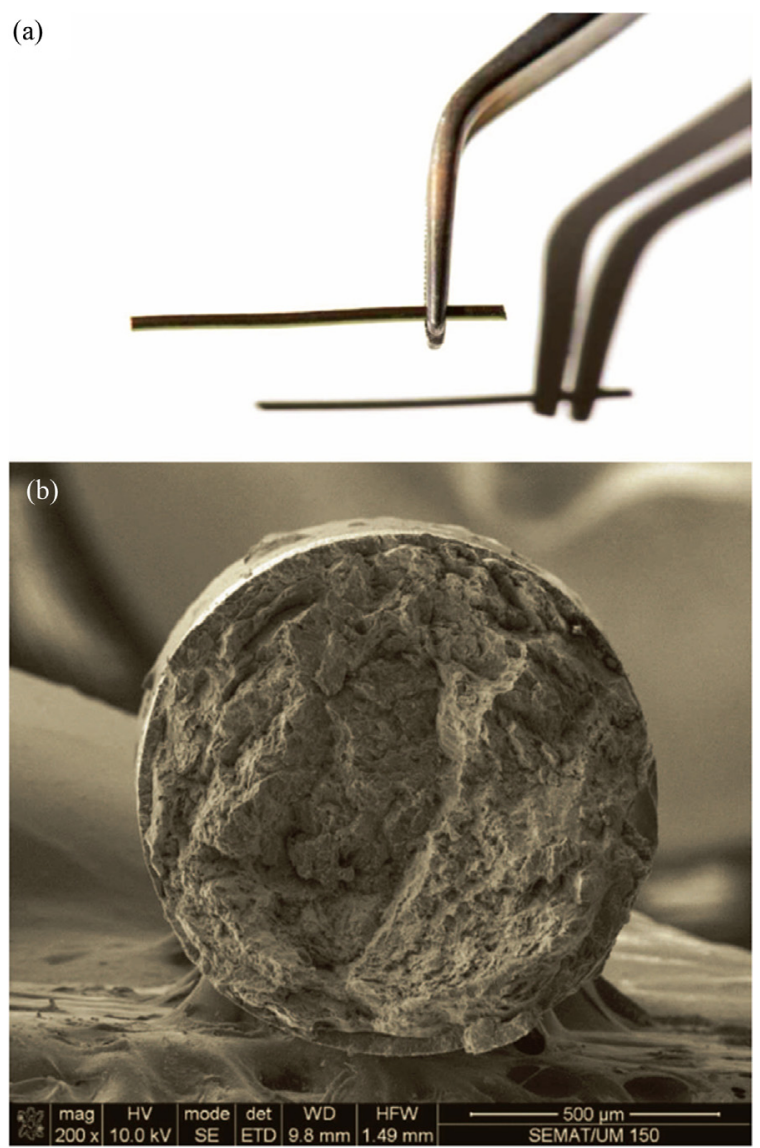

Fig. 9. Pure P3HT fibers with diameter $\sim 1 \mathrm{~mm}$ : (a) image of a pure free-standing P3HT fiber processed at $100^{\circ} \mathrm{C}$; (b) SEM cross sectional view of a fiber processed at $150{ }^{\circ} \mathrm{C}[73]$ (reprinted with permission). (a)

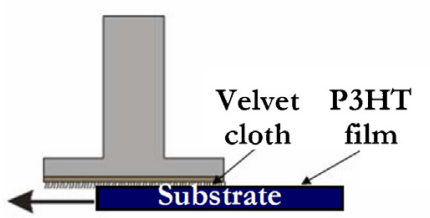

(b)

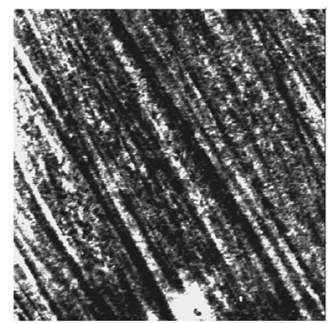

Fig. 10. Schematic illustration of the rubbing method (a) and the AFM image of a rubbed P3HT film (b) [76] (reprinted with permission).
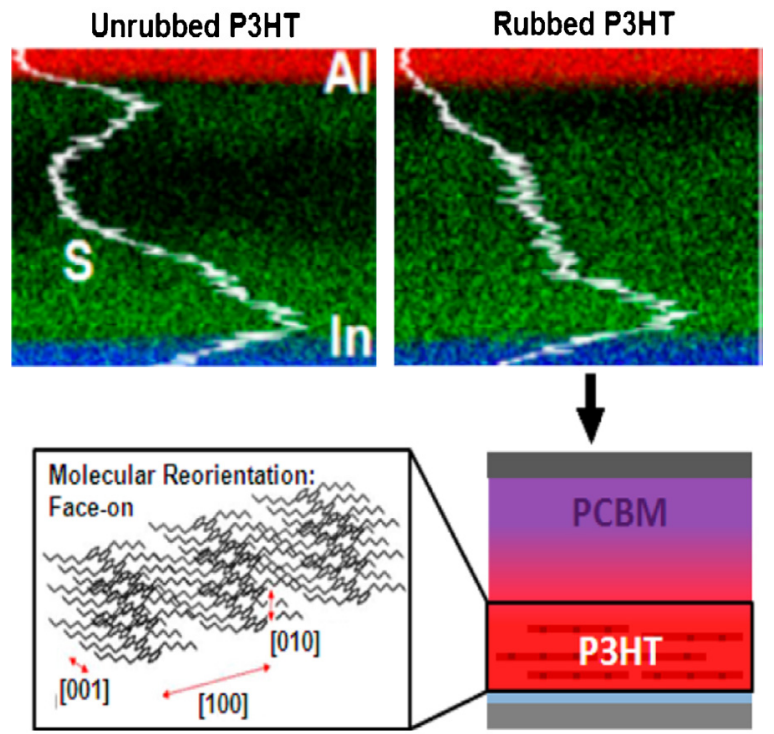

Fig. 11. Top: EDS element mapping and plots (white line) of sulfur counts along the cross section of devices obtained for the unrubbed layer (left) and after rubbing the P3HT layer 5 times (right). The detected elements are aluminum (red), sulfur (green), and indium (blue). Down: Schematic representation of: P3HT molecular orientation (left) in the bilayer solar cell (right) [77] (reprinted with permission). (For interpretation of the references to color in this figure legend, the reader is referred to the web version of this article.)

\subsection{Template wetting}

This fabrication method involves the use of a template having cylindrical nanopores as a shape-defining mold for polymers. Among the mold templates, porous anodic aluminum oxide (porous alumina) is the most widely used [81]. O'Carroll et al. [38] first reported the use of a melt assisted pore template wetting using porous alumina for preparing polymer semiconductor nanowires for optically pumped lasers. After deposition of a thin PFO film by spin coating and heating to the melt, vacuum annealing facilitated the melt infiltration into the nanopores of the porous template applied conformally to the PFO film. Following cooling and solidification of the PFO discrete cylindrical polymer wires with diameters on the order of $300 \mathrm{~nm}$, and lengths of several micrometers with well-defined end faces were obtained (see Fig. 12). This method provides great versatility given the variability in the diameter and length of the pores that can be utilized. It is also a low cost method that provides a long range ordered arrangement of homogeneous pores and allows the preparation of different types of 1D polymer nanostructures such as ordered

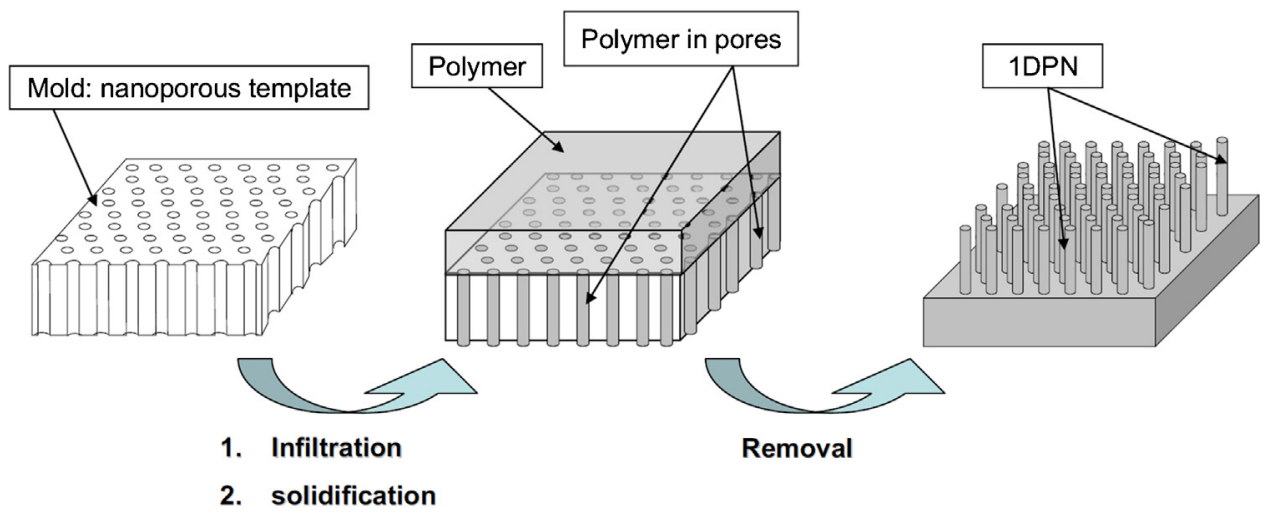

Fig. 12. Template wetting method scheme [81] (reprinted with permission). 


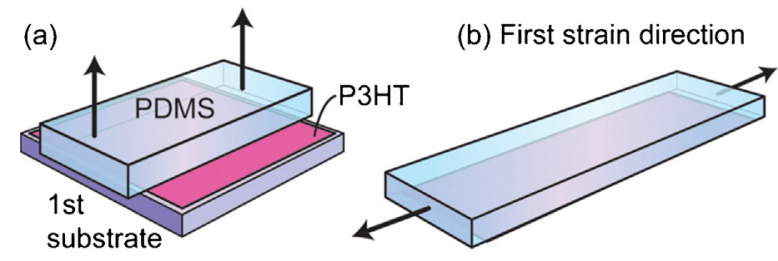

(d)

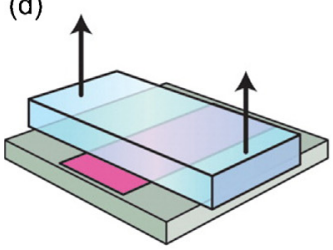

(e) Second strain direction

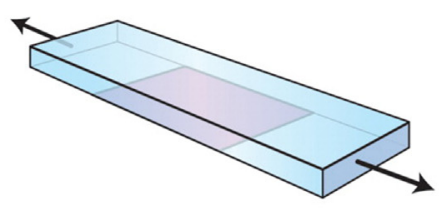

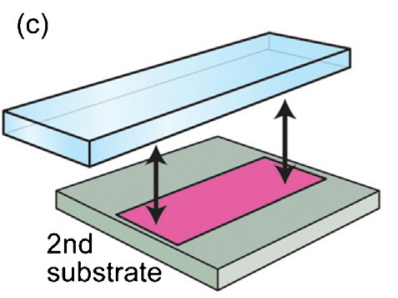

(f)

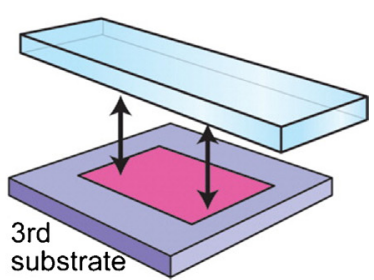

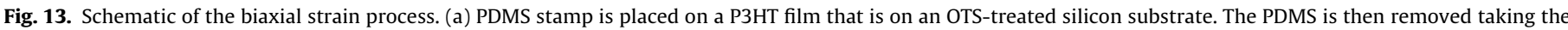

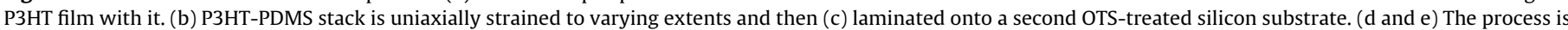

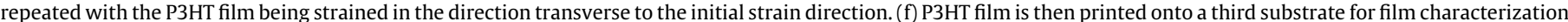
[92] (reprinted with permission).

arrays of low aspect ratio nanocolumns and high aspect ratio free nanowires and nanotubes, etc [81].

Following this work, the template wetting assisted technique has been adapted from using polymer melts, to include polymer solutions and blends. The approach has been widely used for the production of large area micro- and nano-ordered structures mainly for application in polymer solar cells [22,82-85]. For instance, Palacios et al. prepared P3HT microtubes and microfibers by melt-assisted macroporous silicon [84]. Wang et al. used a porous alumina template to prepare vertical aligned core-shell nanorods of P3HT and PCBM from the melt that were successfully used in polymer solar cells, reaching $2 \%$ efficiency [22]. The formation of P3HT nanopillars from nanoporous anodic alumina using melt wetting has also been shown to produce a high degree of alignment of polymers chains in nanopores, which produced an electrical conductivity approximately three times higher than that of a P3HT non-oriented film [85]. However, control of the surface wetting is required to affect orientation as shown by Martín et al. who showed that different wetting regimes exist when preparing P3HT nanowires and nanotubes in anodic alumina templates [83]. At $260^{\circ} \mathrm{C}$ and $280^{\circ} \mathrm{C}$ different wetting regimes were observed associated with different internal structures in the P3HT melt. At $260^{\circ} \mathrm{C}$ there is only a partial wetting regime thus favoring solid nanowires formation. At this temperature the P3HT is organized into a smectic mesophase where the translational motion of the P3HT molecule through the phase-separated structure involved an enthalpic penalty, which prevents the molecular diffusion required for achieving the complete wetting regime. On the other hand, the melt is structurally isotropic at $280^{\circ} \mathrm{C}$, which promotes the complete wetting regime, yielding nanotubes [83].

\subsection{Stretching}

The stretching technique has been used by a number of groups for obtaining orientation in conjugated polymeric films [86]. Recently, Yasuda et al. $[87,88]$ reported organic field-effect transistors (OFETs) based on stretch-oriented regioregular P3HT films. Their optical absorption spectra using polarized light indicated that the parallel to perpendicular dichroic absorption ratio was 2.7 at $626 \mathrm{~nm}$ providing clear evidence that the $\pi$-conjugated P3HT chains are highly oriented parallel to the stretching direction. The field-effect hole mobility parallel to the stretching direction was 3.4 times larger compared to that perpendicular to the stretching direction.
Scavia et al. [89] have studied the effect of stretching the stamp during micro-contact printing of P3HT. They stretched the PDMS stamp before P3HT deposition giving rise to an orientation of P3HT fibrils into the final printed layer along the stretching direction.

The effect of uniaxial tensile strains on the photovoltaic properties of organic solar cells based on two different conjugated polymers and their blends with (PCBM) has been investigated by Lipomi et al. [90]. The two conjugated polymers studied were poly(3-hexylthiophene) (P3HT) and a donor-acceptor polymer whose repeat unit comprises a diketo pyrrolo-pyrrole moiety, thiophene, thienothiophene, and thiophene (DPPT-TT). The stretchable substrate, transparent electrode, and top electrode used in these studies were poly(dimethylsiloxane) (PDMS), poly(3,4ethylenedioxythiophene): poly(styrenesulfonate) (PEDOT:PSS), and eutectic gallium-indium (EGaIn), respectively. It was shown that the high elastic modulus of P3HT:PCBM correlates with the tendency of P3HT:PCBM to fracture at low strains. PEDOT:PSS functions as an adhesion layer of the bulk heterojunction films to the PDMS and thereby increases the crack-onset strain from $<2 \%$ to $8 \%$ for P3HT:PCBM and from 6\% to 12\% for DPPT-TT:PCBM. However, cracks dominated the characteristics of the devices under strain where the differences observed in the response to strain between the two tested devices were correlated to the unequal brittleness of the polymer:fullerene films. They also observed that devices based on both P3HT and DPPT-TT exhibit increased open-circuit voltage with strain, being more significant for devices containing P3HT.

DeLongchamp's group [91,92] developed a novel method of stretching they called "strain-alignment" of P3HT films. Fig. 13 shows the method used either for axial or biaxial alignment. In axial alignment, they observed that the polymer backbone was aligned in the direction of applied strain resulting in a large chargemobility anisotropy, where the in-plane mobility increased in the applied strain direction and decreased in the perpendicular direction. In the aligned film, charge transport parallel to the polymer backbone within a P3HT crystal was strongly favored over other crystallographic directions. Strain alignment induced significant re-orientation from the originally highly edge-on orientation to the face-on oriented crystalline regions of the film and therefore hole mobility parallel to the backbone was high. (Fig. 14). The alignment approach evolved an optical dichroic ratio of 4.8 and a charge-mobility anisotropy of 9 .

Later, his group [92] characterized the $\pi$-stacking direction in P3HT films by biaxially straining films in orthogonal directions. They observed that the unstrained films have a broad $\pi$-stacking 
(a) edge-on

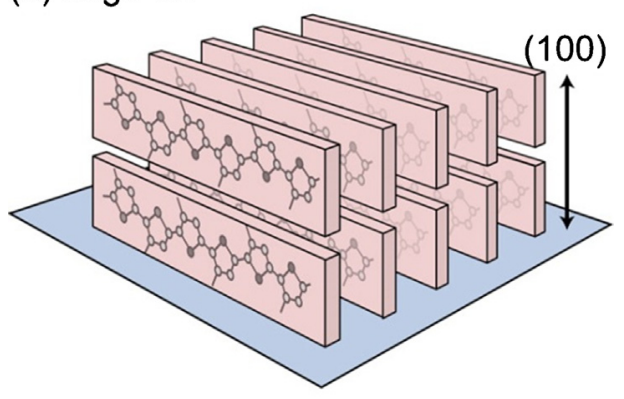

(b) face-on

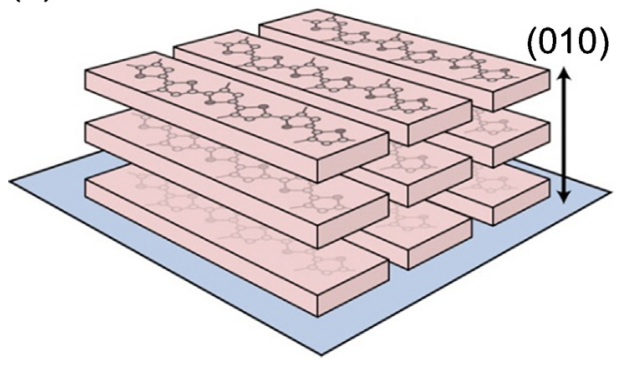

control that is difficult to achieve with solvent-based processing. This review explores the work to date that has been undertaken on solventless processing of conjugated polymers. The results of these studies show that the application of these methods hold significant promise and could replace some of the solution processing steps currently used in for device construction.

\section{Conflict of interest statement}

The authors confirm that there is no conflict of interest regarding a financial supporter.

\section{Acknowledgments}

This work was supported by FCT (Foundation for Science and Technology-PORTUGAL) through the program PEstC/CTM/LA0025/2013 (Strategic Project-LA 25-2013-2014) and by the European Regional Development Fund (FEDER) through the program COMPETE (project PTDC/CTM-POL/120843/2010). L. Brandão is grateful to FCT for the post-doc grant (SFRH/BPD/41233/2007).

\section{References}

Fig. 14. P3HT backbone stacking orientation relative to a substrate for an edge-on (a) and a face-on (b) stacking configuration [92] (reprinted with permission).

orientation with both edge-on and face-on crystals, whereas the biaxially strained films have highly face-on packing (Fig. 14). They characterized the charge transport in an organic thin-film transistor (OTFT) configuration, showing that the saturated field effect mobility in the biaxially strained films is greater than that for unstrained films for channel lengths $\leq 10 \mu \mathrm{m}$, being the channel length the distance between source and drain. The mobilities were found to have different channel-length dependence, attributed primarily to differences in the field-dependent charge-transport behavior, resulting in the mobility being comparable for channel lengths of $20 \mu \mathrm{m}$. They suggest that edge-on packing is not a prerequisite for relatively high-field-effect mobility in P3HT-based OTFTs.

\section{Conclusions}

Polymer processing such as thin film formation can be achieved using a wide variety of methods. In the laboratory the use of solution processing is very widely used to produce thin films for organic electronic devices, with techniques such as spin- or solutioncasting, doctor blade coating, ink-jet printing and so on. This is particularly true for polymers or large organic molecules where alternative approaches, such as vacuum deposition that are used with small, more volatile molecules, are not possible or are impractical. However, the use of solvents as the processing medium does play a very significant role in the final device behavior. Whilst solvents are widely used, it does also require the organic molecules to be soluble in standard solvents, often requiring addition of solubilizing groups on to the active component of the molecule. Such chemical attachments will have some (even if slight) effect on the electronic properties of the molecule, but in addition makes the resulting molecule form a very different solid state morphology than its base molecule. The effect is perhaps most noticeable by the change in the crystallinity and crystal structure.

For many reasons the polymer industry for the most part processes polymers in the melt or solid state. The use of solvents is not widely used in large volume operations, and yet the general processing methods can lend themselves to small volumes of polymer and afford a number of unique opportunities in morphological

[1] C.K. Chiang, et al., Electrical conductivity in doped polyacetylene, Phys. Rev. Lett. 39 (17) (1977) 1098-1101.

[2] H. Shirakawa, et al., J. Chem. Soc., Chem. Commun. (1977) 578-580.

[3] (www.scopus.com), Query (KEY(conjugated polymer) OR KEY(semicondutor polymer) OR KEY(organic semiconductor) OR KEY(conductive polymer)), Access date: October, 2013.

[4] A. Laforgue, L. Robitaille, Fabrication of poly-3-hexylthiophene/polyethylene oxide nanofibers using electrospinning, Synth. Met. 158 (14) (2008) 577-584.

[5] C. Heck, T. Mizokuro, N. Tanigaki, Fabrication of oriented thin films composed of polyfluorene and oligothiophene, and application for polarized white light emitting devices, J. Phys. Conf. Ser. 417 (1) (2013).

[6] R. Hibino, et al., Emission gain-narrowing from melt-recrystallized organic semiconductors, Adv. Mater. 14 (2) (2002) 119-122.

[7] HELIATEK. [cited 2014 30-06-2014]; Available from: 〈http://www.heliatek. com/newscenter/presse/?lang=en $>$.

[8] L. Perrin, et al., Fullerene-based processable polymers as plausible acceptors in photovoltaic applications, J. Polym. Sci., Part B: Polym. Phys. 51 (4) (2013) 293-302.

[9] C.N. Hoth, et al., On the effect of poly(3-hexylthiophene) regioregularity on inkjet printed organic solar cells, J. Mater. Chem. 19 (30) (2009) 5398-5404.

[10] J.S. Yu, et al., Silver front electrode grids for ITO-free all printed polymer solar cells with embedded and raised topographies: prepared by thermal imprint, flexographic and inkjet roll-to-roll processes, Nanoscale 4 (19) (2012) 6032-6040.

[11] N. Espinosa, et al., Solar cells with one-day energy payback for the factories of the future, Energy Environ. Sci. 5 (1) (2012) 5117-5132.

[12] F.C. Krebs, et al., The OE-A OPV demonstrator anno domini 2011, Energy Environ. Sci. 4 (10) (2011) 4116-4123.

[13] R. Søndergaard, et al., Roll-to-roll fabrication of polymer solar cells, Mater. Today $15(1-2)(2012) 36-49$.

[14] T.R. Andersen, et al., Aqueous processing of low-band-gap polymer solar cells using roll-to-roll methods, ACS Nano 5 (5) (2011) 4188-4196.

[15] T.T. Larsen-Olsen, et al., Simultaneous multilayer formation of the polymer solar cell stack using roll-to-roll double slot-die coating from water, Sol. Energy Mater. Sol. Cells 97 (2012) 22-27.

[16] Z. Bao, A.J. Lovinger, Soluble regioregular polythiophene derivatives as semiconducting materials for field-effect transistors, Chem. Mater. 11 (9) (1999) 2607-2612.

[17] A. Afzali, C.D. Dimitrakopoulos, T.O. Graham, Photosensitive pentacene precursor: synthesis, photothermal patterning, and application in thin-film transistors, Adv. Mater. 15 (24) (2003) 2066-2069.

[18] J.H. Edwards, W.J. Feast, A new synthesis of poly(acetylene), Polymer 21 (6) (1980) 595-596.

[19] P.T. Herwig, K. Müllen, Soluble pentacene precursor: synthesis, solid-state conversion into pentacene and application in a field-effect transistor, Adv. Mater. 11 (6) (1999) 480-483.

[20] L.H. Jimison, et al., Charge-transport anisotropy due to grain boundaries in directionally crystallized thin films of regioregular poly(3-hexylthiophene), Adv. Mater. 21 (16) (2009) 1568-1572.

[21] H. Sirringhaus, et al., Mobility enhancement in conjugated polymer field-effect transistors through chain alignment in a liquid-crystalline phase, Appl. Phys. Lett. 77 (3) (2000) 406-408.

[22] H.S. Wang, et al., Ordered polythiophene/fullerene composite core-shell nanorod arrays for solar cell applications, Nanotechnology 20 (7.) (2009). 
[23] B.C. Thompson, J.M.J. Fréchet, Polymer-fullerene composite solar cells, Angew. Chem. Int. Ed. 47 (1) (2008) 58-77.

[24] X.T. Hao, et al., Log-rolling alignment in friction-transferred light-emitting conjugated polymer thin films, Macromolecules 43 (24) (2010) 10475-10480.

[25] T. Erb, et al., Correlation between structural and optical properties of composite polymer/fullerene films for organic solar cells, Adv. Funct. Mater. 15 (7) (2005) 1193-1196.

[26] G. Li, et al., Investigation of annealing effects and film thickness dependence of polymer solar cells based on poly(3-hexylthiophene), J. Appl. Phys. 98 (4) (2005).

[27] L.H. Nguyen, et al., Effects of annealing on the nanomorphology and performance of poly(alkylthiophene):fullerene bulk-heterojunction solar cells, Adv. Funct. Mater. 17 (7) (2007) 1071-1078.

[28] F. Padinger, R.S. Rittberger, N.S. Sariciftci, Effects of postproduction treatment on plastic solar cells, Adv. Funct. Mater. 13 (1) (2003) 85-88.

[29] X. Yang, et al., Nanoscale morphology of high-performance polymer solar cells, Nano Lett. 5 (4) (2005) 579-583.

[30] S. Bertho, et al., Effect of temperature on the morphological and photovoltaic stability of bulk heterojunction polymer:fullerene solar cells, Sol. Energy Mater. Sol. Cells 92 (7) (2008) 753-760.

[31] J. Jo, et al., Time-dependent morphology evolution by annealing processes on polymer:fullerene blend solar cells, Adv. Funct. Mater. 19 (6) (2009) 866-874.

[32] S. Nagamatsu, et al., Effects of molecular alignment on carrier transport in organic transistors, Synth. Met. 137 (1-3) (2003) 923-924.

[33] S. Nagamatsu, et al., Backbone arrangement in friction-transferred regioregular poly(3-alkylthiophene)s, Macromolecules 36 (14) (2003) 5252-5257.

[34] K.R. Amundson, et al., An in-plane anisotropic organic semiconductor based upon poly(3-hexyl thiophene), Thin Solid Films 414 (1) (2002) 143-149.

[35] T. Mizokuro, C. Heck, N. Tanigaki, Orientation of $\alpha$-sexithiophene on frictiontransferred polythiophene film, J. Phys. Chem. B 116 (1) (2012) 189-193.

[36] O. Inganäs, G. Gustafsson, C. Svensson, Melt processable polymer electronics, Synth. Met. 41 (3) (1991) 1095-1101.

[37] C. Müller, et al., Crystalline-crystalline poly(3-hexylthiophene)-polyethylene diblock copolymers: solidification from the melt, Polymer 49 (18) (2008) 3973-3978

[38] D. O'Carroll, I. Lieberwirth, G. Redmond, Melt-processed polyfluorene nanowires as active waveguides, Small 3 (7) (2007) 1178-1183.

[39] L. Qiu, et al., Low-temperature melt processed polymer blend for organic thinfilm transistors, J. Mater. Chem. 22 (36) (2012) 18887-18894

[40] K. Yoshino, et al., Conducting polymer fibre prepared by melt-spinning method from fusible polythiophene derivative, Polym. Commun. 28(11)(1987) 309-310.

[41] M.A. Baklar, et al., Solid-state processing of organic semiconductors, Adv. Mater. 22 (35) (2010) 3942-3947.

[42] Y. Yao, H. Dong, W. Hu, Ordering of conjugated polymer molecules: recent advances and perspectives, Polym. Chem. 4 (2013) 5197-5205.

[43] M. Brinkmann, et al., Orienting semi-conducting pi-conjugated polymers, Macromol. Rapid Commun. 35 (1) (2014) 9-26.

[44] A.M. Hiszpanski, Y.-L. Loo, Directing the film structure of organic semiconductors via post-deposition processing for transistor and solar cell applications, Energy Environ. Sci. 7 (2) (2014) 592-608.

[45] I. Botiz, N. Stingelin, Influence of molecular conformations and microstructure on the optoelectronic properties of conjugated polymers, Materials 7 (3)(2014) 2273-2300.

[46] K.R. Makinson, D. Tabor, Friction and transfer of polytetrafluoroethylene, Nature 201 (4918) (1964) 464-466.

[47] J.C. Wittmann, P. Smith, Highly oriented thin films of poly(tetrafluoroethylene) as a substrate for oriented growth of materials, Nature 352 (6334) (1991) 414-417.

[48] H. Hansma, et al., Molecular resolution of thin: highly oriented poly(tetrafluoroethylene) films with the atomic force microscope, Polymer 33 (3) (1992) 647-649.

[49] D. Fenwick, et al., Characterization of friction-deposited polytetrafluoroethylene transfer films, J. Appl. Polym. Sci. 50 (7) (1993) 1151-1157.

[50] F. Motamedi, et al., Polymer friction-transfer layers as orienting substrates, J. Polym. Sci., B: Polym. Phys. 32 (3) (1994) 453-457.

[51] N. Tanigaki, K. Yase, A. Kaito, Oriented films of poly( $p$-phenylene) by frictiondeposition and oriented growth in polymerization, Mol. Cryst. Liq. Cryst. Sci. Technol., Sect. A 267 (1) (1995) 335-340.

[52] N. Tanigaki, et al., Highly oriented films of poly(dimethylsilylene) by friction deposition, Polymer 36 (12) (1995) 2477-2480.

[53] N. Tanigaki, K. Yase, A. Kaito, Oriented films of insoluble polymers by the friction technique, Thin Solid Films $273(1-2)(1996)$ 263-266.

[54] N. Tanigaki, et al., Oriented thin films of conjugated polymers: polysilanes and polyphenylenes, Thin Solid Films $331(1-2)(1998) 229-238$.

[55] N. Tanigaki, K. Yase, A. Kaito, Mol. Cryst. Liq. Cryst. 267 (1995) 335-340.

[56] N. Tanigaki, et al., Thin Solid Films 331 (1998) 22.

[57] N. Tanigaki, C. Heck, T. Mizokuro, Oriented thin films of polyaniline by friction transfer method, Mol. Cryst. Liq. Cryst. 505 (2009) 318-324.

[58] N. Tanigaki, et al., Molecular orientation of poly(3-butylthiophene) frictiontransferred films, Thin Solid Films 518 (2) (2009) 853-856.

[59] N. Tanigaki, C. Heck, T. Mizokuro, Oriented thin films of perylenetetracarboxylic diimide on friction-transferred polymer films, in: Ninth International
Conference on Nano-Molecular Electronics (ICNME2010), Physics Procedia (Elsevier), Kobe, 2011.

[60] C. Heck, et al., Oriented polyfluorene films dye-doped for whitening of polarized electroluminescent devices, Jpn. J. Appl. Phys. 50 (4 PART 2.) (2011).

[61] S. Nagamatsu, et al., Side-chain effects on friction-transferred polymer orientation, Polym. J. 39 (12) (2007) 1300-1305.

[62] S.P. Li, et al., Friction transfer deposition of ordered conjugated polymer nanowires and transistor fabrication, Appl. Phys. Lett. 87 (6) (2005).

[63] T. Mizokuro, et al., Orientation control of regioregular-poly(3dodecylthiophene) films formed by the friction-transfer method and the performance of organic photovoltaic devices based on these films, J. Appl. Polym. Sci. 131 (8.) (2014)

[64] A. Rodrigues, et al., Thermal stability of P3HT and P3HT:PCBM blends in the molten state, Polym. Test. 32 (7) (2013) 1192-1201.

[65] H. Gaspar, et al., Increase in thermo-oxidation stability of conjugated polymers at high temperatures, Polym. Test. 34 (2014) 183-191.

[66] K. Yoshino, et al., Conducting polymer fiber prepared by melt-spinning method from fusible polythiophene derivative, Polym. Commun. 28 (11)(1987) 309-310.

[67] J.E. Österholm, et al., Melt and solution processable poly(3-alkylthiophenes) and their blends, Synth. Met. 28 (1-2) (1989) 435-444.

[68] J. Laakso, J.E. Österholm, P. Nyholm, Conducting polymer blends, Synth. Met. $28(1-2)(1989) 467-471$.

[69] M. Pomerantz, et al., Processable polymers and copolymers of 3alkylthiophenes and their blends, Synth. Met. 41 (3) (1991) 825-830.

[70] C. Müller, et al., Enhanced charge-carrier mobility in high-pressure-crystallized poly(3-hexylthiophene), Macromolecules 44 (6) (2011) 1221-1225.

[71] J. Fanous, et al., Crystalline and conductive poly(3-hexylthiophene) fibers, Macromol. Mater. Eng. 297 (2) (2012) 123-127.

[72] M. Treier, et al., Solid-solid transfer of organic semiconductors for field-effect transistor fabrication, J. Mater. Chem. 20 (41) (2010) 9018-9021.

[73] A. Rodrigues, et al., Low temperature solid state processing of pure P3HT fibers, AIP Adv. 3 (5) (2013)

[74] G. Bernardo, et al., Solid-state low-temperature extrusion of P3HT ribbons, Appl. Phys. A (2014), http://dx.doi.org/10.1007/s00339-014-8622-x, In Press.

[75] R. Noriega, et al., A general relationship between disorder: aggregation and charge transport in conjugated polymers, Nat. Mater. 12 (11) (2013) $1037-1043$.

[76] G. Derue, et al., Structuration of semiconducting polymer thin films by nanorubbing, in: IECON 2006-32nd Annual Conference on IEEE Industrial Electronics, Paris, 2006.

[77] V. Vohra, et al., Enhanced vertical concentration gradient in rubbed P3HT:PCBM graded bilayer solar cells, J. Phys. Chem. Lett. 3 (13) (2012) 1820-1823.

[78] L. Hartmann, et al., 2D versus 3D crystalline order in thin films of regioregular poly(3-hexylthiophene) oriented by mechanical rubbing and epitaxy, Adv. Funct. Mater. 21 (21) (2011) 4047-4057.

[79] L. Hartmann, et al., Large-scale simultaneous orientation of CdSe nanorods and regioregular poly(3-hexylthiophene) by mechanical rubbing, Macromolecules 46 (15) (2013) 6177-6186.

[80] L. Biniek, et al., Large scale alignment and charge transport anisotropy of pBTTT films oriented by high temperature rubbing, Macromolecules 46 (10) (2013) 4014-4023.

[81] J. Martín, et al., Tailored polymer-based nanorods and nanotubes by template synthesis: from preparation to applications, Polymer 53 (6) (2012) 1149-1166.

[82] M. Kokonou, et al., Polymeric nanowires and nanopillars fabricated by template wetting, J. Nanopart. Res. 15 (4) (2013).

[83] J. Martín, A. Nogales, M. Martín-González, The smectic-isotropic transition of P3HT determines the formation of nanowires or nanotubes into porous templates, Macromolecules 46 (4) (2013) 1477-1483.

[84] R. Palacios, et al., Semiconducting P3HT microstructures: fibres and tubes obtained from macroporous silicon template, Phys. Status Solidi RRL 2 (5) (2008) 206-208.

[85] A. Santos, et al., Fabrication and characterization of high-density arrays of P3HT nanopillars on ITO/glass substrates, Sol. Energy Mater. Sol. Cells 94 (7) (2010) $1247-1253$.

[86] M. Soga, Y. Kishimoto, N. Sonoda, Orientation and conductivity of polyacetylene, Synth. Met. $41(1-2)(1991) 146$.

[87] T. Yasuda, L. Han, T. Tsutsui, Fabrication of stretch-oriented regioregular poly(3hexylthiophene) film and its application to organic field-effect transistors, J. Photopolym. Sci. Technol. 22 (6) (2009) 713-717.

[88] T. Yasuda, Anisotropic carrier transport properties of stretch-oriented $\pi$ conjugated polymers in organic field-effect transistors, Phys. Status Solidi C: Curr. Top. Solid State Phys. 8 (2) (2011) 604-606.

[89] G.Scavia, W. Porzio, S. Destri, Micro-contact printing of poly(3-hexylthiophene) as a tool to improve orientation and ordering of the P3HT layer, Cryst. Res. Technol. 46 (8) (2011) 823-826.

[90] D.J. Lipomi, et al., Toward mechanically robust and intrinsically stretchable organic solar cells: evolution of photovoltaic properties with tensile strain, Sol. Energy Mater. Sol. Cells 107 (2012) 355-365.

[91] B. O'Connor, et al., Anisotropic structure and charge transport in highly strainaligned regioregular poly(3-hexylthiophene), Adv. Funct. Mater. 21 (19) (2011) 3697-3705.

[92] D. Gargi, et al., Charge transport in highly face-on poly(3-hexylthiophene) films, J. Phys. Chem. C 117 (34) (2013) 17421-17428. 